\title{
Prioritization of the essentials in the spending patterns of Canadian households experiencing food insecurity
}

\author{
Andrée-Anne Fafard St-Germain and Valerie Tarasuk* \\ Department of Nutritional Sciences, Faculty of Medicine, University of Toronto, Toronto, Ontario, \\ Canada, M5S 3E2
}

Submitted 21 September 2017: Final revision received 15 January 2018: Accepted 7 February 2018: First published online 21 March 2018

\begin{abstract}
Objective: Food insecurity is a potent determinant of health and indicator of material deprivation in many affluent countries. Food insecurity is associated with compromises in food and housing expenditures, but how it relates to other expenditures is unknown. The present study described households' resource allocation over a 12-month period by food insecurity status.

Design: Expenditure data from the 2010 Survey of Household Spending were aggregated into four categories (basic needs, other necessities, discretionary, investments/assets) and ten sub-categories (food, clothing, housing, transportation, household/personal care, health/education, leisure, miscellaneous, personal insurance/pension, durables/assets). A four-level food insecurity status was created using the adult-specific items of the Household Food Security Survey Module. Mean dollars spent and budget share by food insecurity status were estimated with generalized linear models adjusted first for household size and composition, and subsequently for after-tax income quartiles.

Setting: Canada.

Subjects: Population-based sample of households from the ten provinces ( $n$ 9050). Results: Food-secure households had higher mean total expenditures than marginally, moderately and severely food-insecure households ( $P$-trend $<0 \cdot 0001$ ). As severity of food insecurity increased, households spent less on all categories and sub-categories, except transportation, but they allocated a larger budget share to basic needs and smaller shares to discretionary spending and investments/assets. The downward trends for dollars spent on basic needs and other necessities became non-significant after accounting for income, but the upward trend in the budget shares for basic needs persisted.

Conclusions: The spending patterns of food-insecure households suggest that they prioritized essential needs above all else.
\end{abstract}

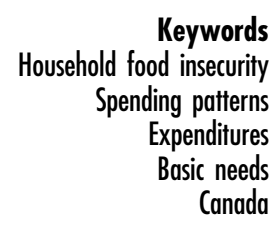

Household food insecurity is increasingly recognized as an important public health problem in many affluent countries, including Canada ${ }^{(1-4)}$. Empirical evidence suggests that experiencing inadequate or insecure access to food due to financial constraints is a strong determinant of physical and mental health across the life cycle ${ }^{(5-8)}$, and a growing number of studies indicates the presence of a dose-response relationship between the severity of the experience and risk of poor health outcomes ${ }^{(9-14)}$. In Canada, where there is a universal health-care system, food insecurity has also been associated with elevated health-care costs independently of other social determinants of health ${ }^{(15,16)}$.

Food insecurity is inextricably linked to households' economic resources. Household income has repeatedly been shown to have an inverse relationship with the risk of food insecurity ${ }^{(17-27)}$ and with the severity of the experience $^{(26-29)}$. Recent studies from Canada also indicate that food insecurity is sensitive to policy interventions that increase household incomes (e.g. through increases in social assistance and child benefits) ${ }^{(30-32)}$. However, evidence suggests that food insecurity is not simply a manifestation of low income, but that it is the consequence of a complex set of economic circumstances and opportunities. Vulnerability to food insecurity has been shown to be influenced by income stability ${ }^{(17)}$, access to assets and savings ${ }^{(17-20)}$ and costs of living $^{(22-25,33-35)}$. Other independent risk factors, often associated with greater economic and social vulnerability, have also been identified in Canada. Examples include Aboriginal status, lone parenthood, lower education, renting rather than owning one's home and reliance on 
income assistance programmes ${ }^{(20,25,26,29)}$. The body of research highlights that food insecurity reflects economic hardship arising from a dynamic, multifactorial process.

Although food insecurity focuses on material deprivation that manifests as food access problems, there are indications that the deprivation experienced by foodinsecure households pervades other domains of consumption. Qualitative research among low-income households has long documented that food insecurity occurs in a context of competing demands for scarce resources and that food-insecure households make tradeoffs in multiple spheres of their lives ${ }^{(36-41)}$. Analyses from the USA have shown that food-insecure households tend to have lower food expenditures ${ }^{(27,42-46)}$, but evidence from the USA and Canada indicates that food insecurity often coexists alongside substandard housing ${ }^{(11,47-50)}$, unstable housing ${ }^{(50,51)}$, having difficulty paying essential bills like rent, mortgage and utilities ${ }^{(11,47-49,52-54)}$, and, more specific to the US context, being unable to afford medical care when needed ${ }^{(47,48,53,54)}$. A small study of low-income urban families in Canada also demonstrated that the severity of food insecurity is associated with greater odds of borrowing money for rent, delaying bill payments, living in substandard housing and giving up services $^{(55)}$. The findings suggest that the material wellbeing of food-insecure households is compromised in numerous ways and that the compromises increase with the severity of food insecurity.

Characterizing the extent of the deprivation experienced by food-insecure households is critical to our broader understanding of the problem of food insecurity, but previous studies have provided only a partial depiction of the compromises made by food-insecure households by focusing on a few, discrete indicators of hardship ${ }^{(47-55)}$ or on specific expenditures, such as food $^{(27,42-46)}$ and housing ${ }^{(49)}$. More comprehensive analyses of household spending have long been used to contrast the material well-being of population subgroups ${ }^{(56-63)}$. Generally, lower spending on diverse goods and services and greater proportions of the budget allocated towards basic needs are indicative of lower relative material well-being, especially when differences are observed between population subgroups stratified by some measure of economic disadvantage $^{(60-64)}$. To date, in-depth assessments of household spending in the context of food insecurity in affluent countries have been thwarted by a paucity of data, but such analyses can shed light on the consumption and material well-being of food-insecure households. Drawing on a unique, population-based survey, the present study aimed to: (i) describe the allocation of economic resources over a 12-month period among Canadian households reporting different levels of food insecurity; and (ii) examine the influence of household income on the association between food insecurity status and households' resource allocation, recognizing that household income is a strong predictor of both consumption and food insecurity.

\section{Methods}

\section{Data and sample}

Data were obtained from the 2010 cycle of the Survey of Household Spending (SHS), a cross-sectional survey administered annually by Statistics Canada to collect detailed information on household expenditures ${ }^{(65)}$. The sampling frame consisted of all households living in the ten provinces, except for individuals living in institutions, members of the Canadian Forces living in military camps and people living on First Nations reserves; these exclusions represented approximately $2 \%$ of the population of the ten provinces. Information on demographic and socioeconomic characteristics as well as regular and large infrequent expenditures were collected during an inperson interview. The Household Food Security Survey Module (HFSSM) was added to the interview questionnaire of the 2010 cycle. Households were also asked to complete a diary for all daily expenditures that were not collected during the interview for a 2 -week period. To improve the accuracy of the expenditures reported and reduce respondents' burden, households were encouraged to consult personal records during the interview and had the option of providing receipts of daily expenditures instead of recording them in the diary ${ }^{(65)}$. Annual income for the year prior to the survey was retrieved from administrative data tax file (i.e. income tax returns) for most households in the sample; otherwise, annual income was reported during the interview. Statistics Canada imputed missing income and expenditures and annualized all expenditures with multiplying factors appropriate for the reporting reference period. Unavailable information on household food insecurity status was identified as missing. A total of 9062 households completed both the interview and diary components of the survey ${ }^{(65)}$, and the final analytic sample for the present study included all households with a measurement of household food insecurity status ( $n$ 9050).

\section{Housebold food insecurity status}

Household food insecurity is monitored in Canada and the USA using the eighteen-item HFSSM ${ }^{(1,46)}$. The HFSSM is a validated experience-based scale structured to reflect a severity continuum ranging from anxiety about being unable to afford food, to compromising food quality, to cutting or skipping meals, losing weight or not eating for a whole day because of insufficient money to buy more food over the past 12 months ${ }^{(44,66,67)}$. The module contains an adult and a child component, but an error in the administration of the eight items specific to children during the interview of the 2010 SHS prevented their use to determine household food insecurity status. For the 
present study, answers to the ten items specific to adults were coded as affirmative or negative based on Health Canada's protocol ${ }^{(68)}$. One strength of using only the items specific to adults is that the same items and thresholds are used to determine the food security status of households with and without children ${ }^{(69)}$. Household food insecurity status was expressed as a four-level variable, with food security, marginal, moderate and severe food insecurity defined, respectively, as $0,1,2-5$ and $\geq 6$ affirmative answers ${ }^{(1,68)}$. The cut-offs for moderate and severe food insecurity are based on Health Canada's thresholds ${ }^{(68)}$. Marginal food insecurity was included as a discrete category, given emerging evidence that affirming any item is associated with heightened vulnerability ${ }^{(15,26,27,55)}$.

\section{Household expenditures}

More than 400 expenditures were collected in the interview and diary components of the survey. To contrast spending patterns by severity of household food insecurity, the individual annualized expenditures were first aggregated into ten sub-categories that reflect different consumption purposes, and these sub-categories were further aggregated into four broad categories that provide a more succinct description of resource allocation towards essential and more flexible consumption needs (see Table 1 for detailed description). The four broad categories were basic needs, other necessities, discretionary spending and investments/assets. The sub-categories included in basic needs were consistent with the expenditures included in the definition of a basic standard of living to calculate the low income cut-offs used in Canada $^{(64)}$. The notion of what represents discretionary spending likely varies across households, but the term was used in the present study to refer to more flexible expenditures that may be less critical for daily living and functioning. Total household expenditures were also examined, since it is indicative of the overall economic resources available to households for consumption during the period for which food insecurity was measured.

\section{Covariates for household composition, household size and housebold income}

Household composition is considered a critical factor influencing households' preferences and consumption decisions ${ }^{(57)}$. Given that previous Canadian populationbased studies have shown that food insecurity is related to household composition ${ }^{(20,25,26,29)}$, the number of children below the age of 18 years, the number of adults aged 18-64 years and the number of seniors 65 years of age or more were added as separate continuous variables in the analyses to control for differences in household composition. These three variables also served to account for differences in household size, which is essential when analysing expenditure data since a household's needs generally increase with its size.
Annual household income was expressed as quartiles of after-tax income, which was calculated by subtracting income tax from household incomes obtained from all sources (e.g. wages and salaries, pensions, and government transfers and tax credits). After-tax income was used instead of before-tax income to better reflect the money available for consumption.

\section{Statistical analyses}

Proportions and means with standard deviations were used to describe the sample by food insecurity status. Spending patterns were first examined using the four broad expenditure categories and then using the ten subcategories. Each expenditure category and sub-category was expressed in dollars spent (all dollar values are \$CAN) and proportion of total expenditures, hereafter referred to as budget share. Mean dollars spent and mean budget share for each category and sub-category were estimated by food insecurity status while first controlling only for household composition and size, and then adding quartiles of after-tax household income. The mean estimates were obtained using generalized linear regression models with a gamma distribution and log-link function. The gamma distribution was used because expenditure data are limited to non-negative values ${ }^{(70)}$. The log-link function was selected over the traditional practice of applying a logarithmic transformation to data with a right-skewed distribution because it enables estimations of predicted outcomes in the original scale, avoiding the issues associated with the re-transformation of the log-transformed expenditures $^{(71)}$. Tests for linear trend were conducted to assess the presence of an association between the predicted means and food insecurity status. The $P$ values of the linear trends were adjusted using the Bonferroni method to account for multiple tests (adjusted for twentynine outcomes). A lack of overlap in the $95 \%$ CI of the estimated means was also used as an indication that the means differed from each other ${ }^{(72)}$.

As a sensitivity analysis, more detailed covariates for children's age (i.e. number of children aged $0-2,3-5,6-12$ and 13-17 years) were included in the models, since children's age may be associated with food insecurity ${ }^{(73)}$ and may influence household consumption decisions (e.g. food, housing and leisure choices, childcare, education). These inclusions had minimal impact on the point estimates and did not affect the trends. The results obtained from the more parsimonious models including number of children $<18$ years, number of adults 18-64 years and the number of seniors $\geq 65$ years are reported, but the results including more detailed age groups for children are available upon request.

The sampling and bootstrapped weights provided by Statistics Canada were used to obtain populationrepresentative estimates and to account for the complex survey design. All analyses were conducted with the statistical software package Stata version 15. 
Table 1 Description of the four categories and ten sub-categories of expenditures

\begin{tabular}{|c|c|}
\hline Category/sub-category & Description \\
\hline \multicolumn{2}{|l|}{ Basic needs } \\
\hline Food & Food purchased from stores and restaurants (excludes alcoholic beverages) \\
\hline Clothing & Clothing; footwear; accessories (e.g. gloves, hats, mitts); clothing services (e.g. laundromat, repair services) \\
\hline Housing & $\begin{array}{l}\text { Refers to principal residence only. Mortgage and rent payments; utilities and services (e.g. electricity, heating, } \\
\text { water); tenant's and owner's insurance premiums; condominium charges; property taxes for owners; repairs and } \\
\text { maintenance }\end{array}$ \\
\hline \multicolumn{2}{|l|}{ Other necessities } \\
\hline Transportation & $\begin{array}{l}\text { Public local transportation services (e.g. city bus, train, taxi); gas and other fuels; parking; vehicle leasing } \\
\text { payments; vehicle registration fees; vehicle insurance premiums; repairs and maintenance of vehicle; vehicle } \\
\text { accessories; driving lessons, test and licence fees }\end{array}$ \\
\hline $\begin{array}{l}\text { Household/personal } \\
\text { care }\end{array}$ & $\begin{array}{l}\text { Communication (e.g. landline, cell phone, Internet, postal services); childcare; home maintenance (e.g. cleaning } \\
\text { supplies, snow and garbage removal); maintenance and repairs of household furnishings and equipment; } \\
\text { toiletries, cosmetics, and grooming products and services }\end{array}$ \\
\hline Health/education & $\begin{array}{l}\text { Out-of-pocket medications and health-related services (e.g. eye and dental care); private and public health } \\
\text { insurance premiums; tuition fees for kindergarten, elementary, secondary and post-secondary studies; school } \\
\text { supplies and textbooks }\end{array}$ \\
\hline \multicolumn{2}{|l|}{ Discretionary } \\
\hline Leisure & $\begin{array}{l}\text { Sports and athletics; reading materials; art, music and dance lessons; admission fees (e.g. museum, zoo, arts and } \\
\text { sports events, movie theatre); toys and play equipment; cable television, home entertainment and media (e.g. } \\
\text { music and video); tobacco products and alcoholic beverages; games of chance; travel, accommodations away } \\
\text { from home, camping and child camp; recreational vehicles (e.g. registration, insurance, rental, fuel); owned } \\
\text { property other than principal residence (e.g. mortgage, utilities, insurance premiums, repairs and maintenance) }\end{array}$ \\
\hline Miscellaneous & $\begin{array}{l}\text { Support payments and gifts to non-household members; charitable contributions; funerals; fines; financial, legal } \\
\text { and government services }\end{array}$ \\
\hline \multicolumn{2}{|l|}{ Investments/assets } \\
\hline $\begin{array}{l}\text { Personal insurance/ } \\
\text { pension }\end{array}$ & $\begin{array}{l}\text { Employment insurance premiums; retirement and pension fund payments, annuity contracts and transfer to } \\
\text { registered retirement income funds; life insurance premiums }\end{array}$ \\
\hline Durables/assets & $\begin{array}{l}\text { Represent the value of the durables and assets purchased. Vehicles; recreational vehicles; appliances and } \\
\text { furniture; home theatre, camera and audio equipment; computer; collector's items; major improvements and } \\
\text { alterations to principal residence and other owned real estate (excludes value of purchased home and other } \\
\text { owned properties because mortgage payments already included in housing and leisure, respectively) }\end{array}$ \\
\hline
\end{tabular}

Table 2 Household composition and income by household food insecurity status in a population-based sample of households from the ten provinces of Canada ( $n$ 9050), 2010 Survey of Household Spending

\begin{tabular}{|c|c|c|c|c|c|c|c|c|c|c|c|}
\hline & \multicolumn{2}{|c|}{$\begin{array}{c}\text { Total } \\
(n \text { 9050) }\end{array}$} & \multicolumn{2}{|c|}{$\begin{array}{l}\text { Food secure } \\
(n 7783)\end{array}$} & \multicolumn{2}{|c|}{$\begin{array}{l}\text { Marginally food } \\
\text { insecure }(n 324)\end{array}$} & \multicolumn{2}{|c|}{$\begin{array}{l}\text { Moderately food } \\
\text { insecure }(n 621)\end{array}$} & \multicolumn{2}{|c|}{$\begin{array}{c}\text { Severely food } \\
\text { insecure }(n \text { 322) }\end{array}$} & \multirow[b]{2}{*}{$P^{*}$} \\
\hline & Mean & SD & Mean & SD & Mean & SD & Mean & SD & Mean & SD & \\
\hline No. of children $<18$ years & 0.51 & 0.94 & 0.47 & 0.91 & 0.65 & 0.95 & 0.80 & $1 \cdot 12$ & 0.62 & 1.08 & $<0.0001$ \\
\hline No. of adults $18-64$ years & 1.64 & $1 \cdot 12$ & 1.62 & $1 \cdot 14$ & 1.82 & 1.01 & 1.76 & 0.90 & 1.62 & 1.05 & 0.096 \\
\hline \multirow[t]{2}{*}{ No. of seniors $\geq 65$ years } & 0.34 & 0.64 & 0.38 & 0.67 & $0 \cdot 16$ & 0.39 & $0 \cdot 15$ & 0.41 & 0.13 & 0.40 & $<0.0001$ \\
\hline & \multicolumn{2}{|c|}{$\% †$} & \multicolumn{2}{|c|}{$\% †$} & \multicolumn{2}{|c|}{$\% \dagger$} & \multicolumn{2}{|c|}{$\% \dagger$} & \multicolumn{2}{|c|}{$\% †$} & \\
\hline \multicolumn{12}{|l|}{ After-tax income quartiles } \\
\hline 1 & \multicolumn{2}{|c|}{$25 \cdot 0$} & \multicolumn{2}{|c|}{$20 \cdot 5$} & \multicolumn{2}{|c|}{$42 \cdot 6$} & \multicolumn{2}{|c|}{$46 \cdot 2$} & \multicolumn{2}{|c|}{$59 \cdot 2$} & $<0.0001$ \\
\hline 2 & \multicolumn{2}{|c|}{$25 \cdot 0$} & \multicolumn{2}{|c|}{$24 \cdot 9$} & \multicolumn{2}{|c|}{$22 \cdot 1$} & \multicolumn{2}{|c|}{$26 \cdot 8$} & \multicolumn{2}{|c|}{$26 \cdot 9$} & \\
\hline 3 & \multirow{2}{*}{\multicolumn{2}{|c|}{$\begin{array}{l}25 \cdot 0 \\
25 \cdot 0\end{array}$}} & \multirow{2}{*}{\multicolumn{2}{|c|}{$\begin{array}{l}26 \cdot 6 \\
28 \cdot 0\end{array}$}} & \multirow{2}{*}{\multicolumn{2}{|c|}{$\begin{array}{l}22.9 \ddagger \\
12.5 \ddagger\end{array}$}} & \multirow{2}{*}{\multicolumn{2}{|c|}{$\begin{array}{l}17 \cdot 9 \\
9 \cdot 1 \neq\end{array}$}} & \multirow{2}{*}{\multicolumn{2}{|c|}{$\begin{array}{l}7.6 \ddagger \\
6.4 \ddagger\end{array}$}} & \\
\hline 4 & & & & & & & & & & & \\
\hline
\end{tabular}

*Adjusted Wald tests for equality of means or the Rao-Scott $F$-adjusted $X^{2}$ statistic for categorical variables.

†Column percentages.

fUse with caution, high sampling variability associated with the estimate (CV>16.6\%).

\section{Results}

Household composition differed by food insecurity status; food-secure households tended to have fewer children and more seniors than marginally, moderately and severely food-insecure households (Table 2). Compared with food-secure households, the marginally, moderately and severely food-insecure households were more likely to be in the lowest quartile of after-tax income and less likely to be in the highest quartile.

Food-secure households had higher mean total expenditures (\$69603) than marginally (\$47214), moderately (\$43353) and severely (\$39579) food-insecure households (Fig. 1(a)). There was a significant downward linear trend in mean total expenditures as severity of food insecurity increased $(P<0 \cdot 0001)$. 
(a)

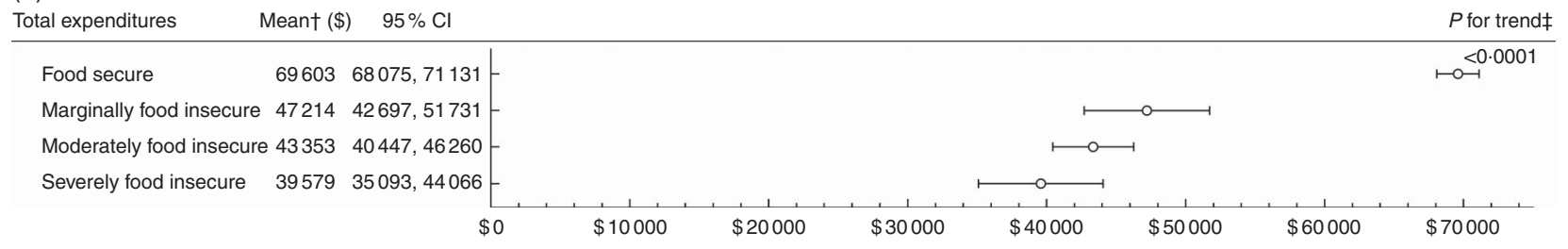

(b)

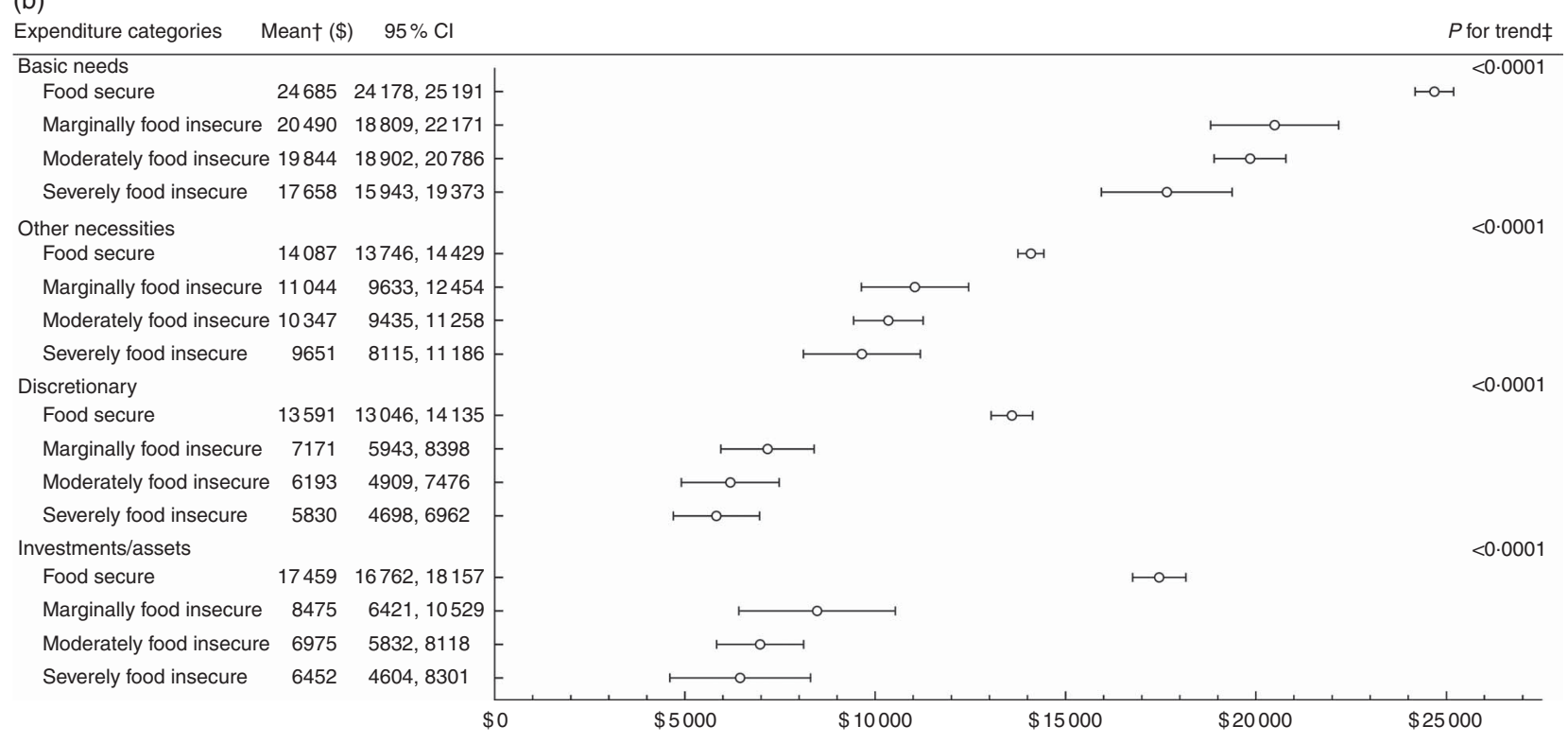

(c)

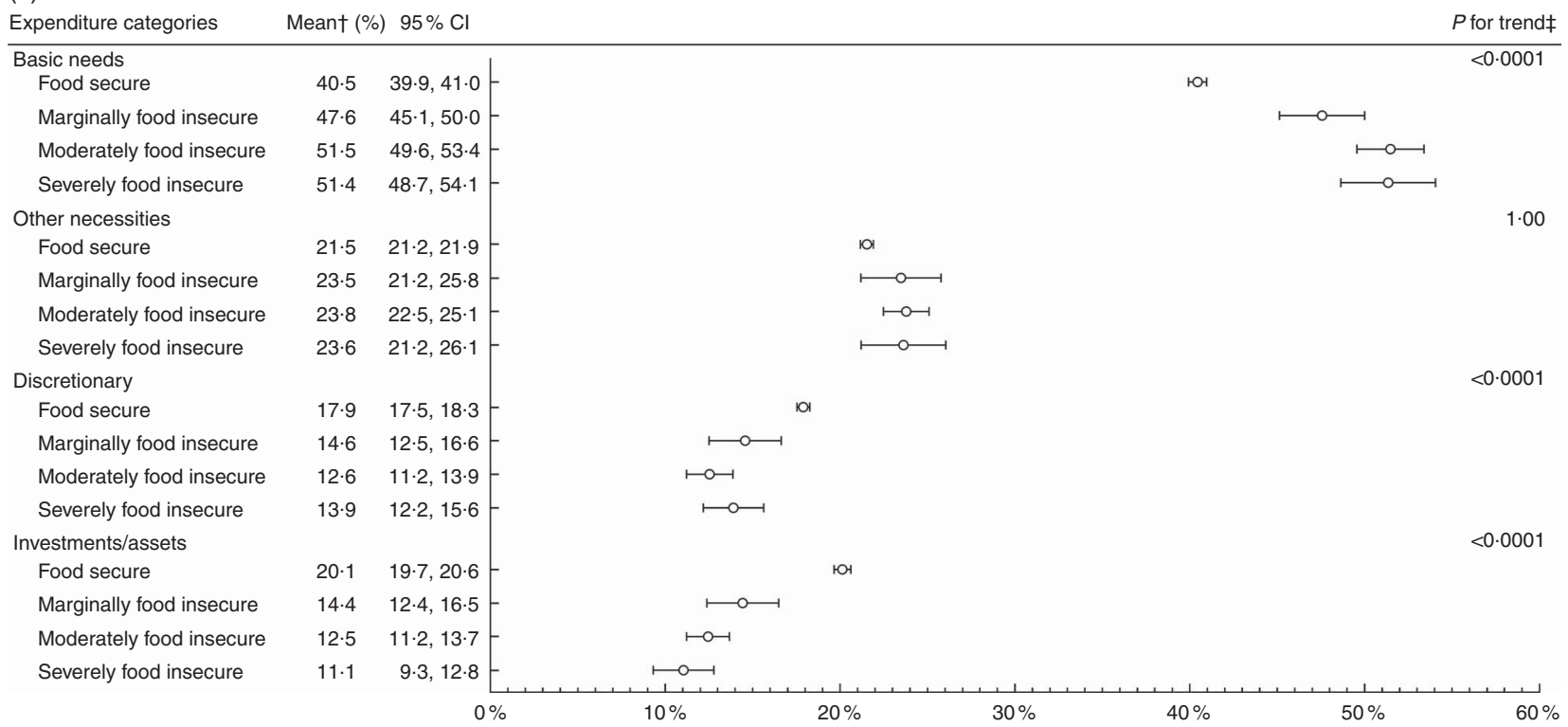

Fig. 1 Mean total expenditures by household food insecurity status* (a), mean dollars spent in each expenditure category by household food insecurity status* (b) and mean budget share allocated to each expenditure category by household food insecurity

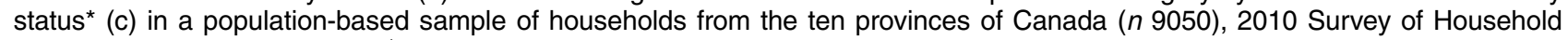
Spending. All dollar values are \$CAN. *Analyses using all households with no missing food insecurity status; food secure ( $n$ 7783), marginally food insecure ( $n$ 324), moderately food insecure ( $n$ 621) and severely food insecure ( $n$ 322). †Predicted means conditional on number of children $<18$ years, number of adults 18-64 years and number of seniors $\geq 65$ years in the household set at observed values; means $(\circ)$ and $95 \% \mathrm{Cl}$ (represented by horizontal bars) estimated while accounting for the complex survey design. ‡Bonferroni-adjusted $P$ value for linear trend test across household food insecurity status; the linear trend test accounted for the complex survey design 
Mean dollars spent and mean budget shares of the full sample for the four broad categories and ten subcategories are presented in the online supplementary material, Supplemental Tables 1 and 2 .

Food-secure households had higher mean expenditures on basic needs, other necessities, discretionary spending and investments/assets than marginally, moderately and severely food-insecure households (Fig. 1(b)). For each of the four categories, there was a highly significant downward trend in mean expenditures as severity of food insecurity increased $(P<0.0001$ for all trends). Of the four categories, basic needs represented the largest expense for all levels of food insecurity, with a mean budget share of 40.5 (95\% CI 39.9, 41.0)\%, $47 \cdot 6$ (95\% CI 45.1, 50.0)\%, $51 \cdot 5$ (95\% CI 49.6, 53.4) \% and 51.4 (95\% CI 48.7, 54.1) \% for the food-secure, marginally, moderately and severely food-insecure households, respectively (Fig. 1(c)). The budget shares allocated to other necessities, discretionary spending and investments/assets tended to be similar among food-secure households, with each one comprising roughly $20 \%$, but they differed for the food-insecure households. Irrespective of the level of severity, foodinsecure households allocated a larger budget share to other necessities than to discretionary spending or investments/assets, while these latter two categories had similar mean budget shares. Food-secure households had lower mean budget share allocated to basic needs but higher mean budget shares allocated to discretionary spending and investments/assets than marginally, moderately and severely food-insecure households. The linear trend indicated that the budget share allocated to basic needs rose with the severity of food insecurity $(P<0.0001)$. In contrast, the budget shares allocated to discretionary spending and investments/assets both declined as severity of food insecurity increased ( $P<0.0001$ for both trends). There was no significant trend for the budget share allocated to other necessities $(P=1 \cdot 00)$.

Similar to the patterns observed for the four broad categories, there were significant downward trends in the dollars spent in each of the ten sub-categories as severity of food insecurity increased, except for transportation which had a non-significant downward trend $(P=0.06$; Fig. 2(a)). Food-secure households had higher mean expenditures on food, clothing, household/personal care, health/education, leisure, miscellaneous, personal insurance/pension and durables/assets than marginally, moderately and severely food-insecure households. For all four levels of food insecurity, housing represented the highest budget share, ranging from $22 \cdot 8$ (95\% CI 22.4, 23.2) \% among food-secure households to $32 \cdot 2$ (95\% CI 29.5, 35.0) \% among severely food-insecure households (Fig. 2(b)). Among the marginally, moderately and severely foodinsecure households, the second highest budget share was allocated to food followed by transportation, whereas food-secure households had similar mean budget shares for food (13.5\%; $95 \%$ CI 13.3, 13.8\%) and durables/assets (13.7\%; 95\% CI 13.2, 14.1\%). The other sub-categories represented $10 \%$ or less of total expenditures for all groups, irrespective of food insecurity status. There were no significant trends for the budget shares allocated to food, clothing, transportation, household/personal care, health/education and leisure. In contrast, the budget share on housing rose with severity of food insecurity $(P<0.0001)$, while the budget shares on miscellaneous $(P=0.0008)$, personal insurance/pension $(P<0.0001)$ and durables/assets $(P<0.0001)$ declined as severity of food insecurity increased.

Accounting for household income in the models generally led to a narrowing in the gaps in mean dollars spent and budget shares between the four levels of food insecurity for all categories and sub-categories (Figs 3 and 4). Most of the trends in mean dollars spent and budget shares across household food insecurity status remained once household income was included. However, the downward trends for mean dollars spent on basic needs, other necessities, housing, household/personal care and personal insurance/pension, and the downward trends for the mean budget shares allocated to discretionary, miscellaneous and personal insurance/pension, became non-significant when household income was included in the models.

\section{Discussion}

Our results indicate that the spending patterns of households experiencing food insecurity differ considerably from those of food-secure households, with substantially lower expenditures and a prioritization of the essentials. The lower spending of food-insecure households compared with their food-secure counterparts across most of the expenditure groupings examined is consistent with the large body of research demonstrating the numerous ways through which the economic resources of food-insecure households are constrained ${ }^{(17-21,24-27)}$. The gap observed in the present study between the mean total expenditures of the food-secure and the marginally, moderately and severely food-insecure households indicates that households experiencing food insecurity have lower overall economic resources available for consumption. Household income represents a primary resource for consumption, and our results suggest that the lower amounts spent on essentials by food-insecure households is a function of their incomes, but the prioritization of the essentials among food-insecure households is not fully explained by their lower incomes.

We found that despite spending less on basic needs, food-insecure households allocated a larger proportion of their budget to these. This prioritization of the budget towards goods and services contributing to basic living highlights the lower relative material well-being of foodinsecure households, particularly at the more severe levels 
(a)

Expenditure sub-categories
Food
Food secure
Marginally food insecure
Moderately food insecure
Severely food insecure
Clothing
Food secure
Marginally food insecure
Moderately food insecure
Severely food insecure
Housing
Food secure
Marginally food insecure
Moderately food insecure
Severely food insecure
Transportation
Food secure
Marginally food insecure
Moderately food insecure
Severely food insecure
Household/personal care
Food secure
Marginally food insecure
Moderately food insecure
Severely food insecure
Health//ducation
Food secure
Marginally food insecure
Moderately food insecure
Severely food insecure
Leisure
Food secure
Marginally food insecure
Moderately food insecure
Severely food insecure
Miscellaneous
Food secure
Marginally food insecure
Moderately food insecure
Severely food insecure
Personal insurance/pension
Food secure
Marginally food insecure
Moderately food insecure
Severely food insecure
Durables/assets
Food secure
Marginally food insecure
Moderately food insecure
Severely food insecure

Meant (\$) $95 \% \mathrm{Cl}$

$8288 \quad 8086,8490$

$\begin{array}{ll}8288 & 8086,8490 \\ 6538 & 5809,7268\end{array}$ $6253 \quad 5819,6688$ $5180 \quad 4507,5852$ $3103 \quad 2965,3241$ $2213 \quad 1884,2543$ 20131653,2372 $1507 \quad 1170,1844$ 1343613092,13780 1183110525,13137 $10816 \quad 9402,12231$ 62186012,6425 $\begin{array}{ll}5205 & 4227,6182 \\ 4877 & 212\end{array}$

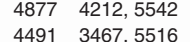
$4410 \quad 4262,4558$
3257 $\begin{array}{ll}4257 & 2834,3680\end{array}$ $3105 \quad 2805,3405$ $3034 \quad 2432,3635$ 34893318,3661 $\begin{array}{ll}2587 & 1995,3179 \\ 2363 & 2020,2706\end{array}$ $2083 \quad 1489,2677$ $7494 \quad 7160,7828$ $3368 \quad 2832,3904$ $3699 \quad 2633,4764$ $6093 \quad 5731,6456$ $3850 \quad 2640,5061$ $\begin{array}{ll}3850 & 2640,5061 \\ 2452 & 1899,3006\end{array}$ $2637 \quad 1728,3546$ $5010 \quad 4838,5182$ $2403 \quad 1957,2850$ 25712181,2961 $1869 \quad 1444,2294$ 1259111937,13245 $\begin{array}{lll}6147 & 4322,7972 \\ 4578 & 3506,5590\end{array}$ $4671 \quad 2945,6398$ $\$ 0$
$P$ for trend

(b)

xpenditure sub-categories Meant (\%) $95 \%$ C

$P$ for trend $\neq$

\begin{tabular}{|c|c|c|c|c|c|c|c|}
\hline Food & & & & & & & $1 \cdot 00$ \\
\hline Food secure & 13.5 & $13 \cdot 3,13 \cdot 8$ & & & a & & \\
\hline Marginally food insecure & 15.5 & $14 \cdot 1,16 \cdot 9$ & & & $\curvearrowleft$ & & \\
\hline Moderately food insecure & $16 \cdot 1$ & $15 \cdot 0,17 \cdot 2$ & & & $\curvearrowleft$ & & \\
\hline Severely food insecure & $14 \cdot 9$ & $13 \cdot 3,16 \cdot 6$ & & & 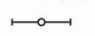 & & \\
\hline Clothing & & & & & & & 1.00 \\
\hline Food secure & $4 \cdot 2$ & $4 \cdot 0,4 \cdot 3$ & 。 & & & & \\
\hline Marginally food insecure & $4 \cdot 6$ & $4 \cdot 0,5 \cdot 3$ & not & & & & \\
\hline Moderately food insecure & $4 \cdot 1$ & $3 \cdot 5,4 \cdot 7$ & that & & & & \\
\hline Severely food insecure & 3.7 & $3 \cdot 0,4 \cdot 5$ & tror & & & & \\
\hline Housing & & & & & & & $<0.0001$ \\
\hline Food secure & $22 \cdot 8$ & $22 \cdot 4,23 \cdot 2$ & & & & rot & \\
\hline Marginally food insecure & 27.5 & $24 \cdot 9,30 \cdot 1$ & & & & & $\longrightarrow$ \\
\hline Moderately food insecure & 31.3 & $29 \cdot 4,33 \cdot 2$ & & & & & $\longmapsto$ \\
\hline Severely food insecure & $32 \cdot 2$ & $29.5,35.0$ & & & & & \\
\hline Transportation & & & & & & & 1.00 \\
\hline Food secure & $9 \cdot 3$ & $9 \cdot 1,9 \cdot 6$ & & a & & & \\
\hline Marginally food insecure & $10 \cdot 9$ & $9 \cdot 0,12 \cdot 7$ & & & & & \\
\hline Moderately food insecure & $10 \cdot 6$ & $9 \cdot 5,11 \cdot 6$ & & $\infty$ & & & \\
\hline Severely food insecure & $10 \cdot 3$ & $8 \cdot 8,11 \cdot 8$ & & $\longmapsto$ & & & \\
\hline Household/personal care & 6.8 & 6.6 .7 .0 & & & & & $1 \cdot 00$ \\
\hline
\end{tabular}

Food secure

$\begin{array}{ll}6.8 & 6 \cdot 6,7 \cdot 0 \\ 7.2 & 6 \cdot 5,7 \cdot 9 \\ 7 \cdot 6 & 7 \cdot 0,8 \cdot 2\end{array}$ Marginally food insecure $\quad 7 \cdot 2 \quad 6 \cdot 5,7 \cdot 9$

$\begin{array}{ll}8.2 & 6 \cdot 8,9 \cdot 7\end{array}$ Health/education

Food secure

$\begin{array}{ll}5 \cdot 4 & 5 \cdot 2,5 \cdot 7 \\ 5 \cdot 4 & 4 \cdot 2 \cdot 6 \cdot 6\end{array}$ Marginally food insecure $\quad 5 \cdot 4 \quad 4 \cdot 2,6 \cdot 6$ Severely food insecure $\quad 4 \cdot 9 \quad 3 \cdot 8,6 \cdot 0$

$<0.0001$

eisure

$0.3 \quad 10 \cdot 0,10 \cdot 6$ \begin{tabular}{lrr} 
Marginally food insecure $\quad 7.3$ & $6.4,8 \cdot 1$ \\
\hline
\end{tabular} $\begin{array}{lll}8.7 & 7.1,10.2\end{array}$

$<0.0001$ $\begin{array}{ll}8 \cdot 7 & 7 \cdot 1,10 \cdot 2 \\ 7 \cdot 6 & 7 \cdot 3,7 \cdot 9\end{array}$ $\begin{array}{lll}\text { Food secure } & 7.6 & 7.3,7.9\end{array}$ Marginally food insecure $\quad 7 \cdot 4 \quad 5 \cdot 2,9 \cdot 6$ Moderately food insecure $\quad 5 \cdot 1 \quad 4 \cdot 2,6 \cdot 0$ Severely food insecure $\quad 5 \cdot 2 \quad 3 \cdot 9,6 \cdot 5$ Personal insurance/pension

$6.5 \quad 6.3,6.7$

Marginally food insecure Marginally food insecure Severely food insecure

$\begin{array}{ll}6.5 & 6 \cdot 3,6 \cdot 7 \\ 4 \cdot 7 & 3 \cdot 6,5 \cdot 9\end{array}$ $\begin{array}{ll}5 \cdot 0 & 4 \cdot 3,5 \cdot 8 \\ 3 & \end{array}$ Food secure

$13.7 \quad 13.2,14 \cdot 1$

$3 \cdot 7 \quad 13 \cdot 2,14 \cdot$ \begin{tabular}{lrl} 
Marginally food insecure $\quad 9.9$ & $8.0,11.8$ \\
\hline & 7.7 & 0.5
\end{tabular}

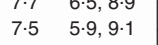

$\int_{10-1}^{2}$

ror

$\stackrel{-\infty}{\infty}$

tro-

rot

ror

ra

Fig. 2 Mean dollars spent in each expenditure sub-category by household food insecurity status* (a) and mean budget share allocated to each expenditure sub-category by household food insecurity status ${ }^{*}$ (b) in a population-based sample of households from the ten provinces of Canada ( $\left.n 9050\right)$, 2010 Survey of Household Spending. All dollar values are $\$ C A N$. *Analyses using all households with no missing food insecurity status; food secure ( $n$ 7783), marginally food insecure ( $n$ 324), moderately food insecure ( $n$ 621) and severely food insecure $(n 322)$. †Predicted means conditional on number of children $<18$ years, number of adults $18-64$ years and number of seniors $\geq 65$ years in the household set at observed

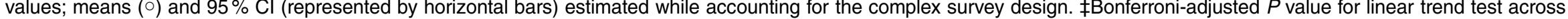
household food insecurity status; the linear trend test accounted for the complex survey design 
(a)

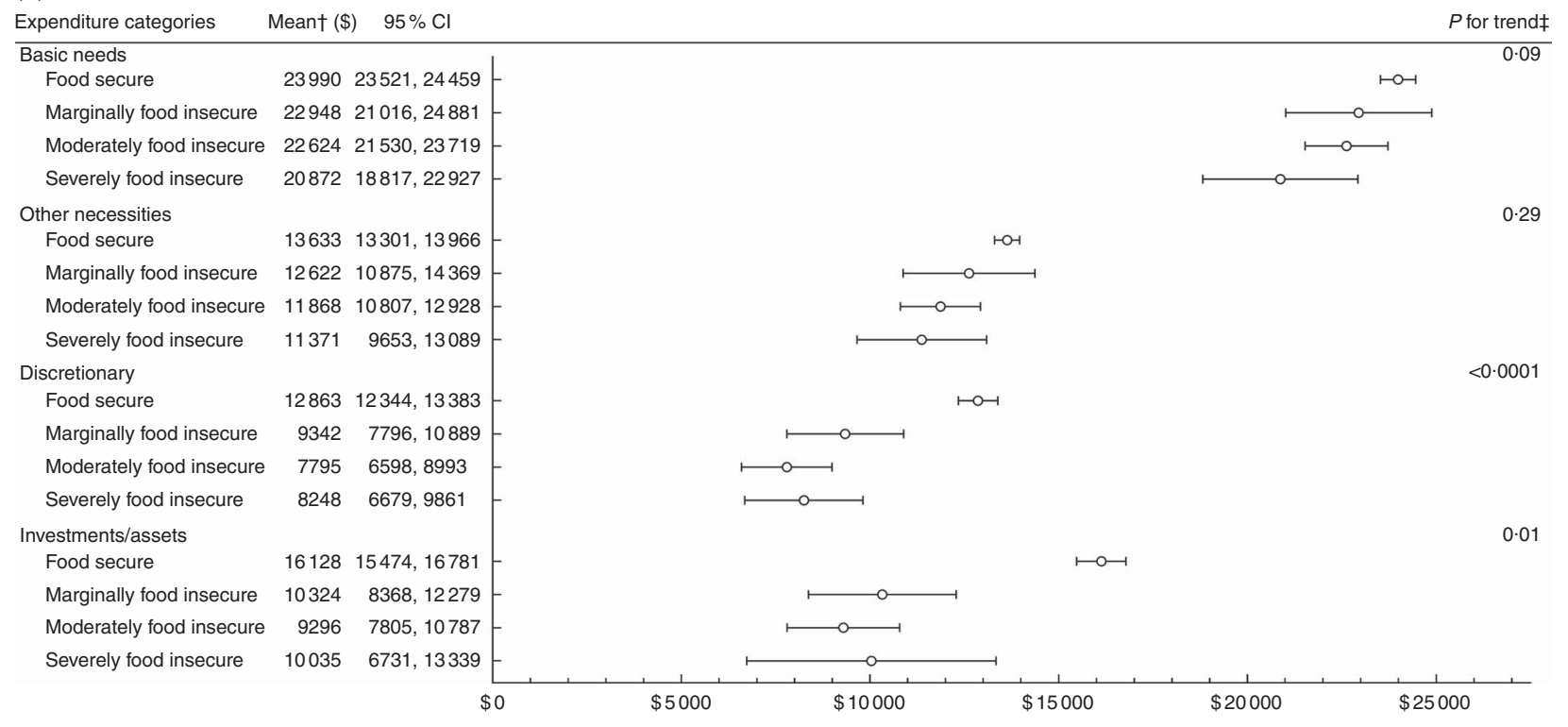

(b)

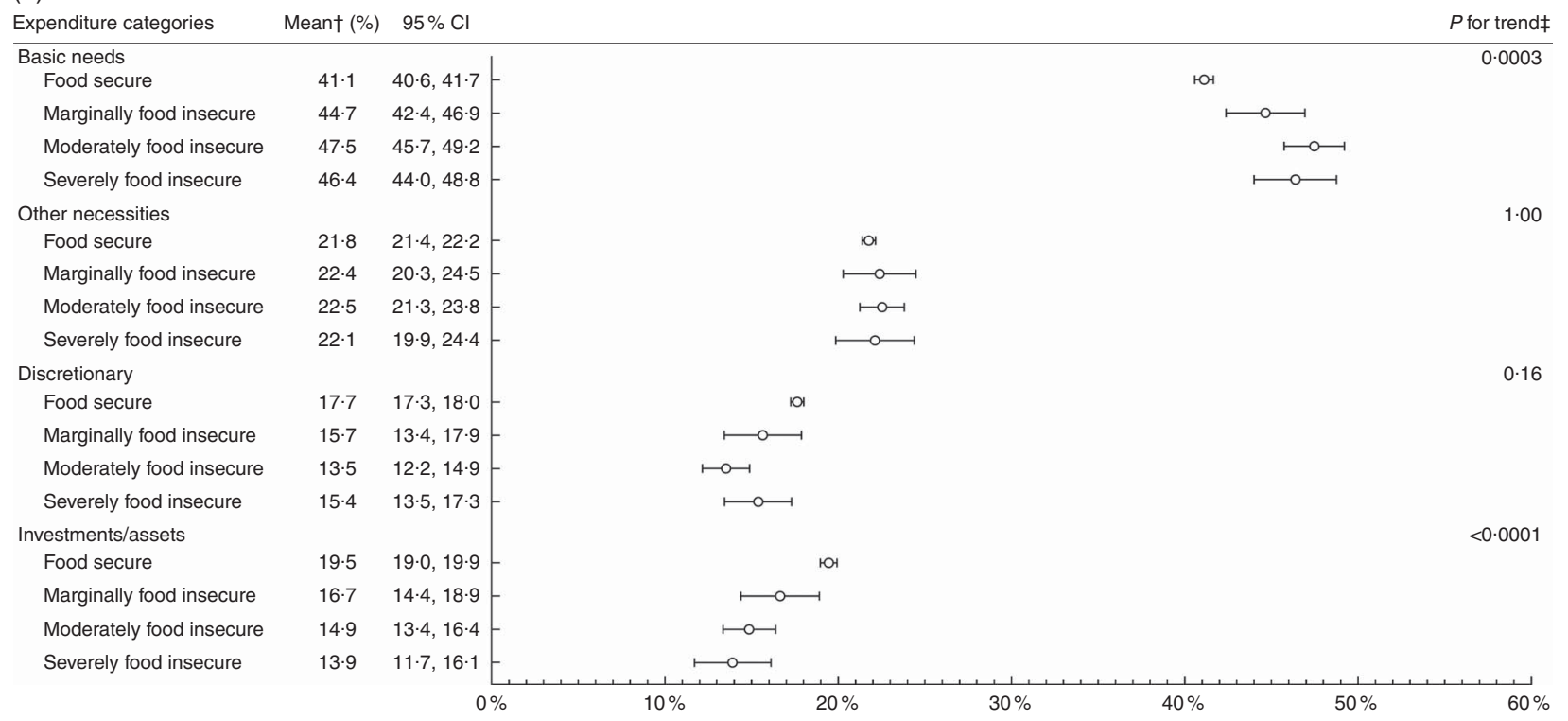

Fig. 3 Mean dollars spent in each expenditure category by household food insecurity status* while controlling for household income (a) and mean budget share allocated to each expenditure category by household food insecurity status ${ }^{\star}$ while controlling for household income (b) in a population-based sample of households from the ten provinces of Canada ( $n$ 9050), 2010 Survey of Household Spending. All dollar values are \$CAN. *Analyses using all households with no missing food insecurity status; food secure ( $n$ 7783), marginally food insecure $(n 324)$, moderately food insecure $(n 621)$ and severely food insecure $(n 322)$. †Predicted means conditional on number of children $<18$ years, number of adults 18-64 years and number of seniors $\geq 65$ years in the household, and quartiles of after-tax household income set at observed values; means $(\circ)$ and $95 \% \mathrm{Cl}$ (represented by horizontal bars) estimated while accounting for the complex survey design. $\ddagger$ Bonferroni-adjusted $P$ value for linear trend test across household food insecurity status; the linear trend test accounted for the complex survey design

of food insecurity. It appears that the prioritization of basic needs was achieved by decreasing the proportion of the budget allocated to discretionary spending and investments/assets. The greatest disparities in mean expenditures between the food-secure and the marginally, moderately and severely food-insecure households were observed for discretionary spending and investments/ assets, while the gaps in mean expenditures on basic needs and other necessities tended to be smaller. Similarly, the largest disparities in mean expenditures between the food-secure and the marginally, moderately and severely food-insecure households were for leisure, miscellaneous spending, personal insurance/pension and durables/ assets. The spending patterns observed in the present 
(a)

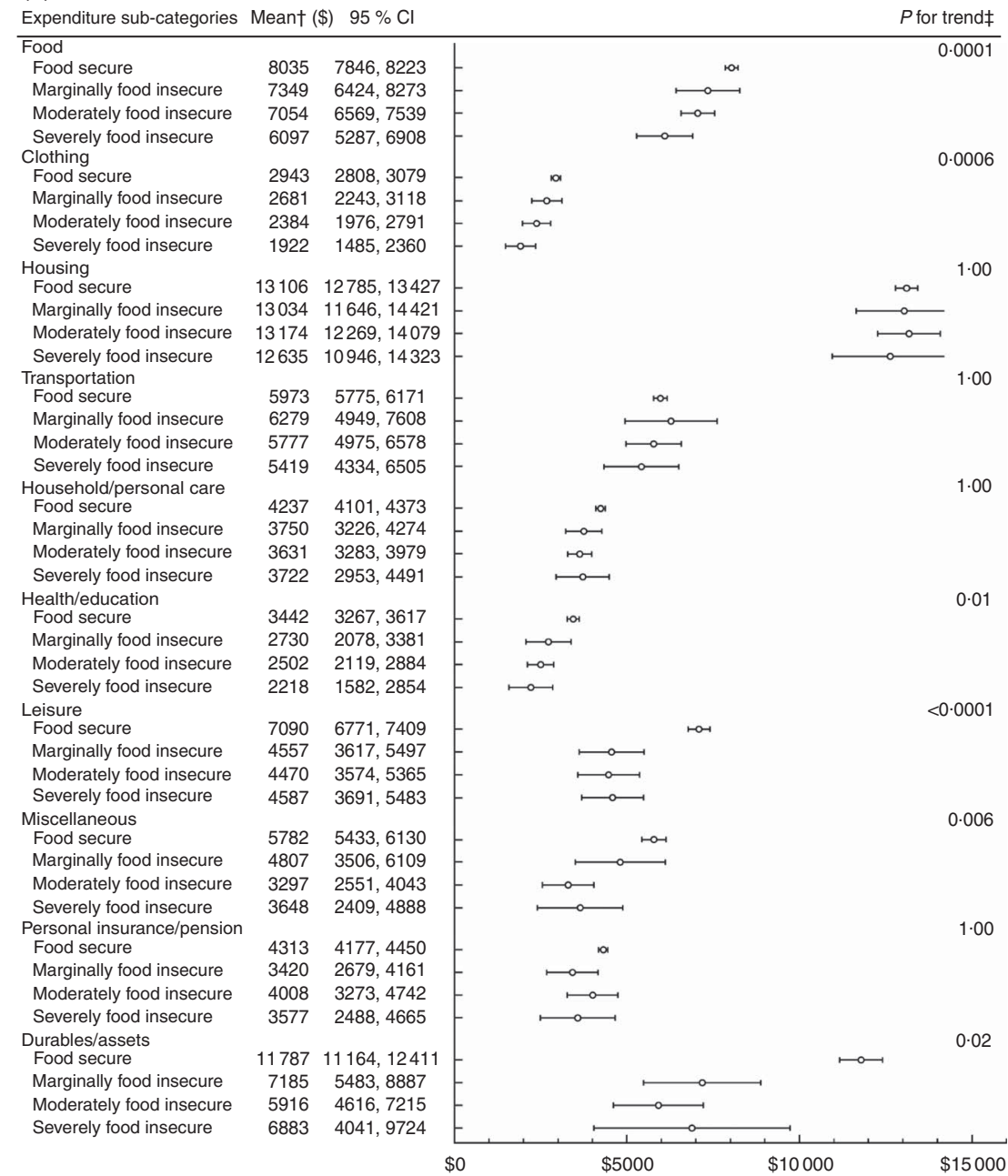

(b)

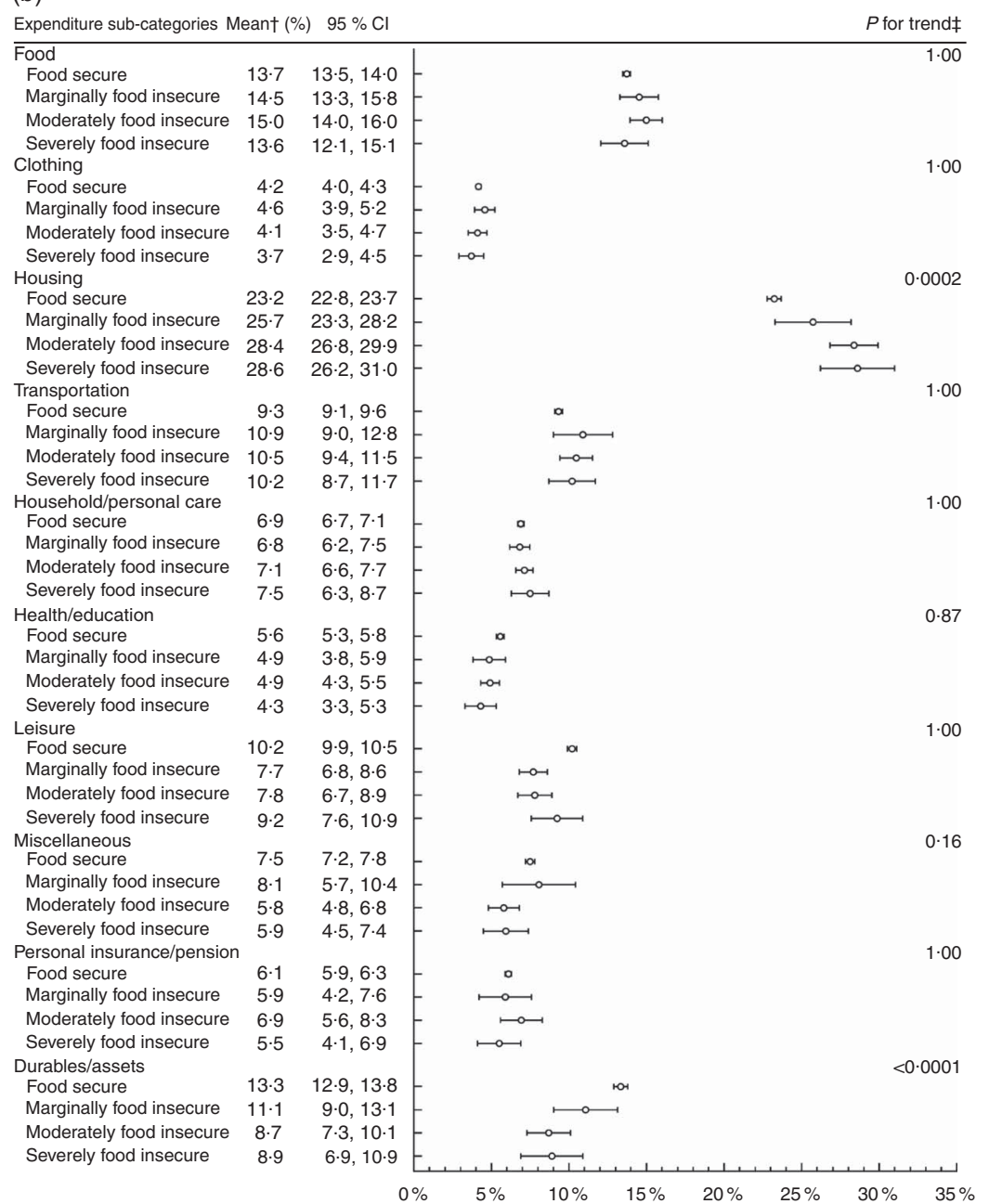

Fig. 4 Mean dollars spent in each expenditure sub-category by household food insecurity status* while controlling for household income (a) and mean budget share allocated to each expenditure sub-category by household food insecurity status* while controlling for household income (b) in a population-based sample of households from the ten provinces of Canada ( $n$ 9050), 2010 Survey of Household Spending. All dollar values are $\$ C A N$. *Analyses using all households with no missing food insecurity status; food secure ( $n$ 7783), marginally food insecure ( $n$ 324), moderately food insecure $(n 621)$ and severely food insecure $(n 322)$. †Predicted means conditional on number of children $<18$ years, number of adults 18-64 years and number of seniors $\geq 65$ years in the household, and quartiles of after-tax household income set at observed values; means ( $($ ) and $95 \%$ Cl (represented by horizontal bars) estimated while accounting for the complex survey design. $\ddagger$ Bonferroni-adjusted $P$ value for linear trend test across household food insecurity status; the linear trend test accounted for the complex survey design 
study indicate purchasing decisions that overall favour the essentials when food insecurity is experienced.

The prioritization of basic needs that we observed among households experiencing food insecurity is consistent with the results of earlier research examining the effects of policy interventions that increased the financial resources of lower-income households on their spending patterns $^{(62,74)}$. For example, a population-based analysis of child benefits in Canada showed that income supplements provided to low-income families led to higher expenditures on food, rent, childcare, education and transportation $^{(74)}$. These shifts in household expenditures following income-based interventions are consistent with findings from a growing number of studies from Canada and the USA that have reported reductions in food insecurity in conjunction with policy interventions that improve the economic resources of lower-income households via cash or in-kind benefits ${ }^{(30-32,75,76)}$.

Consistent with previous US studies ${ }^{(27,42-46)}$, mean food expenditures tended to decline with severity of food insecurity. However, the budget share allocated to food was similar among all four levels of food insecurity, suggesting that food expenditures tended to decline proportionally with total expenditures across food insecurity status. Economic theory posits that the proportion of the budget allocated to food generally increases as total economic resources decline ${ }^{(56,60)}$, but the absence of a trend in the budget share for food in our study may be because the experience of food insecurity indicates compromised food access, with more severe levels of food insecurity reflecting greater food compromises. The inclusion of household income had minimal impact on the patterns observed across household food insecurity status for the dollars spent on food and the proportion of the budget allocated to food, suggesting that these patterns, especially the lower expenditures, are specific to the experience of food insecurity, rather than to the lower income generally associated with food insecurity.

Our finding that the budget share for food is similar across levels of food insecurity raises serious questions about the validity of using the proportion of total spending allocated to food as a proxy for household food security, which is an established practice in the $\mathrm{UK}^{(77)}$. While our finding needs to be confirmed in other country contexts, it highlights the importance of a direct measurement of household food insecurity to monitor the magnitude of the problem.

We found that despite a downward trend in housing expenditures across severity of food insecurity, there was an upward trend in the budget share allocated to housing. These results may indicate that housing expenditures represent a financial burden that cannot easily be reduced to accommodate lower economic resources, which is consistent with ecological studies from Canada and the USA showing a positive association between area-level housing cost and risk of food insecurity ${ }^{(24,25,33)}$. The downward trends in the budget shares allocated to the sub-categories of personal insurance/pension, durables/assets and miscellaneous spending imply a lower prioritization of these goods and services among households experiencing food insecurity. While previous studies have found that households with lower assets and savings are more vulnerable to food insecurity ${ }^{(17-20)}$, our results indicate that during periods of food insecurity, households spend disproportionately less on goods and services that can contribute to future financial security (e.g. pension, personal insurance and durables).

Our results suggest that household income partly contributed to the gaps in mean dollars spent and budget shares observed between levels of food insecurity for all categories and sub-categories, yet many differences in the spending patterns of food-secure and food-insecure households were not fully explained by differences in household income. The lower amounts spent on other necessities and basic needs, especially housing, by food-insecure households appear to have been a function of their incomes, but the allocation of a greater proportion of their budget towards basic needs persisted despite the inclusion of income. In contrast, the lower expenditures on investments/assets, particularly for durables/assets, and discretionary spending among foodinsecure households remained after controlling for income, but only the downward trend in mean budget shares for investments/assets stayed significant. The persisting differences in the spending patterns of food-secure and foodinsecure households after the inclusion of income may suggest that prioritizing basic needs is inherent to the experience of food insecurity.

The spending patterns observed by household food insecurity status reveal that marginally food-insecure households are more similar in their expenditures to moderately and severely food-insecure households than to food-secure households. This finding is consistent with a growing number of studies indicating that households affirming any item(s) on the HFSSM are distinct from fully food-secure households (i.e. those with zero affirmatives) in terms of their sociodemographic profiles ${ }^{(27)}$, vulnerability to other forms of material hardship ${ }^{(55)}$ and risk of poor health outcomes ${ }^{(9,11,13-15)}$. This highlights the importance of including households experiencing a marginal level of food insecurity among the food-insecure rather than the food-secure households to avoid underestimating the magnitude of the problem of household food insecurity and its consequences.

To date, few studies have examined the differences in the economic circumstances of food-insecure households along the severity continuum. Evidence suggests that the odds of experiencing different material hardships rise with the severity of food insecurity ${ }^{(55)}$ and that the severity of food insecurity declines with a gain in employment ${ }^{(28)}$, an increase in income ${ }^{(28)}$ and greater savings and assets ${ }^{(18,19)}$. However, our results indicate considerable similarity in the spending patterns of the marginally, moderately and severely food-insecure households. There are some visible 
trends in the estimated means across the three groups, particularly when examining dollars spent, but the much smaller number of households in each group led to less precise estimates and significant overlap in the confidence intervals. Using a survey with a larger sample of foodinsecure households would likely lead to greater differences in spending patterns. However, it is possible that the reference periods used to measure the expenditure data led to more similarities than differences among the three food-insecure groups. The measurement of food insecurity captures the worst experience in the last 12 months, but it is likely that the severity of food insecurity fluctuates over those 12 months. The reference periods for which the expenditures were reported may not reflect actual spending at the time when the most severe experience of food insecurity occurred.

There is a long history of using household consumption derived from expenditure data as an indicator of material well-being ${ }^{(56-63)}$. However, the SHS lacked information on the prices faced by the households and on the quality of the goods and services purchased, meaning that the expenditures in the present study were a proxy rather than a direct measure of consumption. Lower expenditures among the food-insecure households compared with their food-secure counterparts may not reflect lower consumption of goods and services if they faced lower prices. Yet, it appears unlikely that the food-insecure households comprising this population-based sample faced systematically lower prices across all goods and services, given the evidence from Canada and the USA that living in areas with higher housing ${ }^{(24,25,33)}$, utility $^{(34)}$ and food ${ }^{(23)}$ prices is associated with greater risk of food insecurity.

Measurement error in expenditure data is an important consideration, but the extent to which measurement error varies by household food insecurity status is unknown. Generally, longer reference periods increase the risk of recall bias whereas shorter reference periods tend to increase the variance of the estimates $^{(56)}$. To increase the accuracy of the expenditures reported by respondents, Statistics Canada uses different reference periods (e.g. last 2 weeks for common expenditures like food or last 12 months for infrequent expenditures like large durables) and the expenditures are subsequently annualized. Most of the aggregates created in the present study were susceptible to the limitations of both short and long reference periods since they included expenditures reported for different periods. While the categories and sub-categories created were to some extent arbitrary, we attempted to group individual expenditures into commonly understood and referenced categories and to be as conservative as possible in the expenditures included in basic needs and other necessities. We also separated, when possible, expenditures on non-durables and durables or longer-term investments, since they contribute to consumption and living standards differently ${ }^{(56,57)}$.

For some households in the sample, the annual income used in the analyses may not have reflected the income available during the 12-month period for which food insecurity and the expenditures were measured, because SHS collects income data for the year prior to the survey. Given the evidence that household food insecurity is associated with income shocks ${ }^{(17)}$, these differences in the timing of the measurements may have led to an overestimation of the income of food-insecure households and larger differences in the spending of the food-secure and food-insecure households when controlling for income. Future research should be conducted with contemporaneous measures of income, food insecurity and expenditures to further examine the influence of income on the resource allocation of food-insecure households. Our analyses controlled for household composition, household size and income, but spending decisions may be affected by other household characteristics also associated with food insecurity (e.g. disability, employment, home ownership). Since different household characteristics likely affect certain categories of spending but not others and the direction of effects may vary by category, it is unclear how the inclusion of such variables would affect our results. Although more research is needed to better characterize the relationship between household food insecurity and specific expenditure categories, evidence that food insecurity is a managed process associated with deliberated tradeoffs $^{(11,36-41,47-55,78,79)}$ would suggest that, irrespective of other household characteristics, the prioritization of basic needs is an integral part of the experience of food insecurity.

To our knowledge, the present study is the first population-based analysis of a broad spectrum of household expenditures in the context of food insecurity in an affluent country. Our work adds to previous research on the relationship between discrete expenditure categories and household food insecurity $(27,42-46,49)$ by examining not only the amount spent in different categories but also the proportion of the budget allocated to these, and by considering the severity of food insecurity. The distinct spending patterns observed in the present study indicate that households experiencing food insecurity, including the most marginal level, prioritize essential needs above all else. Our findings lend support to evidence showing that food insecurity is related to constrained financial resources and add to prior qualitative ${ }^{(37-41)}$ and quantitative $e^{(11,47-55)}$ studies documenting the coexistence of food insecurity with compromises in numerous domains of consumption. The pervasiveness of the material deprivation experienced by food-insecure households and the myriad of poor health outcomes related to food insecurity stress the importance of developing effective policy interventions that improve the economic resources of vulnerable households.

\section{Acknowledgements}

Financial support: The present work was supported by a programmatic grant in Health and Health Equity from the 
Canadian Institutes of Health Research (FRN: 115208). The Canadian Institutes of Health Research had no role in the design, analysis or writing of this article. Conflict of interest: None. Authorship: A-A.F.S.G. and V.T. conceived and designed the study, interpreted the data and wrote the manuscript. A-A.F.S.G. conducted the statistical analyses. Both authors read and approved the final manuscript. Ethics of human subject participation: Ethics approval for the present study was obtained from the University of Toronto's Health Sciences Research Ethics Board.

\section{Supplementary material}

To view supplementary material for this article, please visit https://doi.org/10.1017/S1368980018000472

\section{References}

1. Tarasuk V, Mitchell A \& Dachner N (2016) Housebold Food Insecurity in Canada, 2014. Toronto, ON: Research to identify policy options to reduce food insecurity (PROOF).

2. Gundersen C (2013) Food insecurity is an ongoing national concern. Adv Nutr 4, 36-41.

3. Ashton JR, Middleton J \& Lang T (2014) Open letter to Prime Minister David Cameron on food poverty in the UK. Lancet 383, 1631.

4. Loopstra R, Reeves A \& Stuckler D (2015) Rising food insecurity in Europe. Lancet 385, 2041.

5. Gundersen C \& Ziliak JP (2015) Food insecurity and health outcomes. Health Aff (Millwood) 34, 1830-1839.

6. Carmichael SL, Yang W, Herring A et al. (2007) Maternal food insecurity is associated with increased risk of certain birth defects. J Nutr 137, 2087-2092.

7. Mangini LD, Hayward MD, Dong YQ et al. (2015) Household food insecurity is associated with childhood asthma. J Nutr 145, 2756-2764.

8. Power M, Uphoff E, Kelly B et al. (2017) Food insecurity and mental health: an analysis of routine primary care data of pregnant women in the Born in Bradford cohort. J Epidemiol Community Health 71, 324-328.

9. Whitaker RC, Phillips SM \& Orzol SM (2006) Food insecurity and the risks of depression and anxiety in mothers and behavior problems in their preschool-aged children. Pediatrics 118, e859-e868.

10. Laraia BA, Siega-Riz AM, Gundersen C et al. (2006) Psychosocial factors and socioeconomic indicators are associated with household food insecurity among pregnant women. J Nutr 136, 177-182.

11. Cook JT, Black M, Chilton M et al. (2013) Are food insecurity's health impacts underestimated in the US population? Marginal food security also predicts adverse health outcomes in young US children and mothers. Adv Nutr $\mathbf{4}$, 51-61.

12. Davison KM, Marshall-Fabien GL \& Tecson A (2015) Association of moderate and severe food insecurity with suicidal ideation in adults: national survey data from three Canadian provinces. Soc Psychiatry Psychiatr Epidemiol 50, 963-972.

13. Jessiman-Perreault G \& McIntyre L (2017) The household food insecurity gradient and potential reductions in adverse population mental health outcomes in Canadian adults. SSM Popul Health 3, 464-472.

14. Gregory CA \& Coleman-Jensen A (2017) Food Insecurity, Chronic Disease, and Health among Working-Age Adults. Economic Research Report no. EER-235. Washington, DC: US Department of Agriculture, Economic Research Service.
15. Tarasuk V, Cheng J, de Oliveira C et al. (2015) Association between household food insecurity and annual health care costs. CMAJ 187, E429-E436.

16. Fitzpatrick T, Rosella LC, Calzavara A et al. (2015) Looking beyond income and education: socioeconomic status gradients among future high-cost users of health care. $A m \mathrm{~J}$ Prev Med 49, 161-171.

17. Leete L \& Bania N (2010) The effect of income shocks on food insufficiency. Rev Econ Househ 8, 505-526.

18. Huang J, Guo B \& Kim Y (2010) Food insecurity and disability: do economic resources matter? Soc Sci Res 39, 111-124.

19. Guo B (2011) Household assets and food security: evidence from the Survey of Program Dynamics. J Fam Econ Issues 32, 98-110.

20. McIntyre L, Wu X, Fleisch VC et al. (2016) Homeowner versus non-homeowner differences in household food insecurity in Canada. J Hous Built Environ 31, 349-366.

21. Willows ND, Veugelers P, Raine K et al. (2009) Prevalence and sociodemographic risk factors related to household food security in Aboriginal peoples in Canada. Public Health Nutr 12, 1150-1156.

22. Nielsen RB, Garasky S \& Chatterjee S (2010) Food insecurity and out-of-pocket medical expenditures: competing basic needs? Fam Consum Sci Res J 39, 137-151.

23. Gregory CA \& Coleman-Jensen A (2013) Do high food prices increase food insecurity in the United States? Appl Econ Perspect Policy 35, 679-707.

24. Bartfeld J \& Dunifon R (2006) State-level predictors of food insecurity among households with children. J Policy Anal Manage 25, 921-942.

25. Sriram U \& Tarasuk V (2016) Economic predictors of household food insecurity in Canadian metropolitan areas. J Hunger Environ Nutr 11, 1-13.

26. Tarasuk V, Mitchell A, McLaren L et al. (2013) Chronic physical and mental health conditions among adults may increase vulnerability to household food insecurity. $J$ Nutr 143, 1785-1793.

27. Coleman-Jensen AJ (2010) US food insecurity status: toward a refined definition. Soc Indic Res 95, 215-230.

28. Loopstra R \& Tarasuk V (2013) Severity of household food insecurity is sensitive to change in household income and employment status among low-income families. J Nutr $\mathbf{1 4 3}$, 1316-1323.

29. Li N, Dachner N \& Tarasuk V (2016) The impact of changes in social policies on household food insecurity in British Columbia, 2005-2012. Prev Med 93, 151-158.

30. Loopstra R, Dachner N \& Tarasuk V (2015) An exploration of the unprecedented decline in the prevalence of household food insecurity in Newfoundland and Labrador, 2007-2012. Can Public Policy 41, 191-206.

31. Ionescu-Ittu R, Glymour MM \& Kaufman JS (2015) A difference-in-differences approach to estimate the effect of income-supplementation on food insecurity. Prev Med $\mathbf{7 0}$, 108-116.

32. McIntyre L, Dutton DJ, Kwok C et al. (2016) Reduction of food insecurity among low-income Canadian seniors as a likely impact of a guaranteed annual income. Can Public Policy 42, 274-286.

33. Fletcher JM, Andreyeva T \& Busch SH (2009) Assessing the effect of changes in housing costs on food insecurity. J Child Poverty 15, 79-93.

34. Emery JCH, Bartoo AC, Matheson J et al. (2012) Evidence of the association between household food insecurity and heating cost inflation in Canada, 1998-2001. Can Public Policy 38, 181-215.

35. Nord M, Coleman-Jensen A \& Gregory C (2014) Prevalence of US Food Insecurity is Related to Changes in Unemployment, Inflation, and the Price of Food. Economic Research 
Report no. ERR-167. Washington, DC: US Department of Agriculture, Economic Research Service.

36. Campbell CC \& Desjardins E (1989) A model and research approach for studying the management of limited food resources by low income families. J Nutr Educ 21, 162-171.

37. Tarasuk V (2001) Household food insecurity with hunger is associated with women's food intakes, health and household circumstances. J Nutr 131, 2670-2676.

38. Hamelin AM, Beaudry M \& Habicht JP (2002) Characterization of household food insecurity in Quebec: food and feelings. Soc Sci Med 54, 119-132.

39. Williams PL, MacAulay RB, Anderson BJ et al. (2012) 'I would have never thought that I would be in such a predicament': voices from women experiencing food insecurity in Nova Scotia, Canada. J Hunger Environ Nutr 7, 253-270.

40. Buck-McFadyen EV (2015) Rural food insecurity: when cooking skills, homegrown food, and perseverance aren't enough to feed a family. Can J Public Health 106, e140-e146.

41. Knowles M, Rabinowich J, Ettinger de Cuba S et al. (2016) 'Do you wanna breathe or eat?': parent perspectives on child health consequences of food insecurity, trade-offs, and toxic stress. Matern Child Health J 20, 25-32.

42. Cristofar SP \& Basiotis PP (1992) Dietary intakes and selected characteristics of women ages 19-50 years and their children ages $1-5$ years by reported perception of food sufficiency. J Nutr Educ 24, 53-58.

43. Olson CM, Rauschenbach BS, Frongillo EA et al. (1997) Factors contributing to household food insecurity in a rural upstate New York county. Fam Econ Rev 10, 2-17.

44. Hamilton WL, Cook JT, Thompson WW et al. (1997) Household Food Security in The United States in 1995: Technical Report of the Food Security Measurement Project. Alexandria, VA: US Department of Agriculture, Office of Analysis and Evaluation.

45. Gundersen C \& Ribar D (2011) Food insecurity and insufficiency at low levels of food expenditures. Rev Income Wealth 57, 704-726.

46. Coleman-Jensen A, Rabbitt MP, Gregory C et al. (2016) Household Food Security in the United States in 2015. Economic Research Report no. ERR-215. Washington, DC: US Department of Agriculture, Economic Research Service.

47. Ouellette T, Burstein N, Long D et al. (2004) Measures of Material Hardship. Washington, DC: US Department of Health and Human Services, Assistant Secretary for Planning and Evaluation.

48. Heflin C (2006) Dynamics of material hardship in the Women's Employment Study. Soc Serv Rev 80, 377-397.

49. Kirkpatrick SI \& Tarasuk V (2011) Housing circumstances are associated with household food access among lowincome urban families. J Urban Health 88, 284-296.

50. Cutts DB, Meyers AF, Black MM et al. (2011) US housing insecurity and the health of very young children. $A m J$ Public Health 101, 1508-1514.

51. Gundersen C, Weinreb L, Wehler C et al. (2003) Homelessness and food insecurity. J Hous Econ 12, 250-272.

52. Cook JT, Frank DA, Casey PH et al. (2008) A brief indicator of household energy security: associations with food security, child health, and child development in US infants and toddlers. Pediatrics 122, e867-e875.

53. Klesges LM, Pahor M, Shorr RI et al. (2001) Financial difficulty in acquiring food among elderly disabled women: results from the Women's Health and Aging Study. Am J Public Health 91, 68-75.

54. Heflin C (2016) Family instability and material hardship: results from the 2008 Survey of Income and Program Participation. J Fam Econ Issues 37, 359-372.

55. Loopstra R \& Tarasuk V (2013) What does increasing severity of food insecurity indicate for food insecure families? Relationships between severity of food insecurity and indicators of material hardship and constrained food purchasing. J Hunger Environ Nutr 8, 37-49.

56. Deaton A (1997) The Analysis of Household Surveys: A Microeconometric Approach to Development Policy. Baltimore, MD: John Hopkins University Press.

57. Deaton A \& Zaidi S (2002) Guidelines for Constructing Consumption Aggregates for Welfare Analysis. Living Standards Measurement Study Working Paper no. 135. Washington, DC: World Bank.

58. Meyer BD \& Sullivan JX (2003) Measuring the well-being of the poor using income and consumption. J Hum Resour $\mathbf{3 8}$, 1180-1220.

59. Brzozowski M \& Crossley TF (2011) Viewpoint: measuring the well-being of the poor with income or consumption: a Canadian perspective. Can J Econ 44, 88-106.

60. Chai A \& Moneta A (2010) Retrospectives: Engel curves. $J$ Econ Perspect 24, 225-240.

61. Meyer BD \& Sullivan JX (2004) The effects of welfare and tax reform: the material well-being of single mothers in the 1980s and 1990s. J Public Econ 88, 1387-1420.

62. Gregg P, Waldfogel J \& Washbrook E (2006) Family expenditures post-welfare reform in the UK: are lowincome families starting to catch up? Labour Econ 13, 721-746.

63. Kaushal N, Gao Q \& Waldfogel J (2007) Welfare reform and family expenditures: how are single mothers adapting to the new welfare and work regime? Soc Serv Rev 81, 369-396.

64. Income Statistics Division (2013) Low Income Lines, 2011-2012. Catalogue no. 75F0002M, no. 002. Ottawa, ON: Statistics Canada, Income Statistics Division.

65. Income Statistics Division (2012) User Guide for the Survey of Household Spending, 2010. Catalogue no. 62F0026M, no. 1. Ottawa, ON: Statistics Canada, Income Statistics Division.

66. Hamilton WL, Cook JT, Thompson WW et al. (1997) Household Food Security in the United States in 1995: Summary Report of the Food Security Measurement Project. Alexandria, VA: US Department of Agriculture, Office of Analysis and Evaluation.

67. Wunderlich GS \& Norwood JL (editors) (2006) Food Insecurity and Hunger in the United States: An Assessment of the Measure. Washington, DC: National Academy of Sciences.

68. Office of Nutrition Policy and Promotion (2007) Canadian Community Health Survey, Cycle 2.2, Nutrition (2004) Income-Related Housebold Food Security in Canada. Ottawa, ON: Health Canada.

69. Wilde PE (2004) Differential response patterns affect foodsecurity prevalence estimates for households with and without children. J Nutr 134, 1910-1915.

70. Hardin JW \& HiIbe JM (2007) Generalized Linear models and Extensions, 2nd ed. College Station, TX: Stata Press.

71. Manning WG \& Mullahy J (2001) Estimating log models: to transform or not to transform? J Health Econ 20, 461-494.

72. Cumming $G$ (2009) Inference by eye: reading the overlap of independent confidence intervals. Stat Med 28, 205-220.

73. Anderson PM, Butcher KF, Hoynes HW et al. (2014) Beyond Income: What Else Predicts Very Low Food Security Among Children? University of Kentucky Center for Poverty Research Discussion Paper Series no. DP 2014-06. Lexington, KY: University of Kentucky Center for Poverty Research.

74. Jones LE, Milligan KS \& Stabile M (2015) Child Cash Benefits and Family Expenditures: Evidence from the National Child Benefit. NBER Working Paper no. 21101. Cambridge, MA: National Bureau of Economic Research.

75. Schmidt L, Shore-Sheppard L \& Watson T (2016) The effect of safety-net programs on food insecurity. J Hum Resour $\mathbf{5 1}$, 589-614. 
76. Kreider B, Pepper JV, Gundersen C et al. (2012) Identifying the effects of SNAP (food stamps) on child health outcomes when participation is endogenous and misreported. $J \mathrm{Am}$ Stat Assoc 107, 958-975.

77. Department for Environment, Food and Rural Affairs (2009) UK Food Security Assessment: Detailed Analysis. London: DEFRA.
78. Radimer KL, Olson CM \& Campbell CC (1990) Development of indicators to assess hunger. J Nutr 120, 1544-1548.

79. Hadley C \& Crooks DL (2012) Coping and the biosocial consequences of food insecurity in the 21st century. $A m \mathrm{~J}$ Phys Anthropol 149, 72-94. 